\title{
RAZÕES PARA O FRACO USO DOS COMPUTADORES NA ESCOLA
}

\section{Porquoi un faible usage des ordinateurs à l'école?}

Fernando Albuquerque Costa ${ }^{2}$

\section{Resumo}

Tomando como ponto de partida uma reflexão inicial sobre algumas das principais questões que hoje se levantam relativamente à utilização das TIC em contexto educativo, o autor defende a idéia de que mais do que uma questão de apetrechamento das escolas, ela é essencialmente uma questão pedagógica, que passa, sobretudo, por uma preparação adequada de professores e alunos para poderem tirar partido destas novas ferramentas de aprendizagem.

Palavras-chave: Fraco uso dos computadores na escola; Tecnologias e aprendizagem; Aprender com tecnologias.

\section{Résumé}

En considérant comme point de départ une réflexion initiale sur quelquesunes des principales questions qui se posent aujourd'hui à l'égard de l'usage des TIC en milieu éducatif, l'auteur soutient que, au-delà des équipements des établissements scolaires, elle est essentiellement une question pédagogique qui passe surtout par une préparation adéquate des enseignants et des élèves pour qu'ils puissent tirer parti de ces nouveaux outils d'apprentissage.

Mots-clefs: Faible usage des ordinateurs à l'école; Technologie et apprentissage; Apprendre avec des technologies.

1 Uma versão deste texto foi inicialmente publicada nas Actas do X Colóquio da Afirse: COSTA, F. (2001). A propósito da democratização do acesso à Internet pelas escolas. In A. ESTRELA \& J. FERREIRA (Eds.), Tecnologias em Educação. Estudos e Investigações (pp. 135-145). Lisboa: Afirse. No caso de haver interesse em aprofundar estas questões, pode fazê-lo com base na informação disponibilizada no site Aprender Com Tecnologias, da responsabilidade do autor deste artigo. Consultar em http://www.aprendercom.net. No Brasil uma primeira parte deste texto foi originalmente publicada em 2002, em COSTA, Fernando "Elementos para reflexão sobre a integração das TIC na Educação", in Lourdes Marcelino MACHADO, Naura Syria Carapeto FERREIRA (Orgs.) Política e gestão da educação - dois olhares. S.Paulo, SP: DP\&A.

2 Professor da Faculdade de Psicologia e de Ciências da Educação, Universidade de Lisboa, Alameda da Universidade 1649-013 Lisboa, Portugal.

E-mail: f.costa@fpce.ul.pt

Site: www.fcosta.pt.vu 


\section{Nota introdutória}

As novas tecnologias tornaram-se parte integrante da sociedade contemporânea e está ultrapassada a idéia de que os computadores seriam inacessíveis à maioria das pessoas. Por outro lado, generaliza-se também a idéia de que são efetivamente uma poderosa ferramenta para resolver problemas. De fato, na linha do que alguns visionários já tinham idealizado, tais como: Vannevar Bush, Ted Nelson e Douglas Engelbart, entre outros, as novas tecnologias passaram a ser o principal meio de arquivo, transferência ou pesquisa de informação e o principal meio de comunicação, direta ou indireta, entre as pessoas, qualquer que seja a sua condição e o lugar onde se encontrem, sendo usadas rotineiramente em empresas, instituições e outros locais de trabalho.

Porque à Escola se atribui uma importância decisiva na preparação dos cidadãos, parece oportuno perguntar até que ponto tem ela cumprido o seu papel de formar os jovens para uma utilização efetiva, responsável e produtiva das tecnologias hoje disponíveis.

Será apenas uma questão de introduzir mais computadores na escola? Será uma questão de vontade política e de clarificação das opções sobre o papel que os computadores podem desempenhar na aprendizagem? Será que é, sobretudo, uma questão de gerações, como defendem alguns?

Foi o aprofundamento destas e doutras questões que serviu de mote à reflexão a seguir apresentada e que, espero, possa ajudar na construção de uma visão mais ampla das razões que têm colocado as nossas escolas na cauda em termos de uso das TIC, pelo menos ao nível da Europa em que estamos integrados.

\section{Razões baseadas na capacidade econômica e nos recursos financeiros}

Para muitos, a generalização do uso das tecnologias na escola é essencialmente uma questão de capacidade econômica e de recursos financeiros. Segundo esta perspectiva, a questão principal é a de que as tecnologias são muito dispendiosas não só em termos de investimento inicial (instalação de infra-estruturas, aquisição de computadores e periféricos, aquisição de software, etc.), como do investimento resultante da rápida desatualização dessas tecnologias, por sua vez em estreita dependência, quer da velocidade de desenvolvimento tecnológico, quer das estratégias empresariais de comercialização e implantação dos produtos no mercado.

Para, além disso, é necessário não esquecer os avultados investimentos que a introdução das tecnologias requer, por exemplo, em termos de 
investigação e outro tipo de custos mais diretamente relacionados com o funcionamento e manutenção dos sistemas, com a formação de pessoal, com despesas de telecomunicações, etc...

O que esta perspectiva nos diz, em suma, é que não havendo recursos financeiros suficientes para equipar as escolas de acordo com padrões desejáveis e para apoiar de uma forma sustentada o processo, são inevitáveis as diferenças de apetrechamento e conseqüente desigualdade em termos de oportunidades de acesso à informação e ao conhecimento que elas proporcionam.

Harmon (1997) explica, no entanto, que os mesmos problemas, a que alguns chamam de "info-exclusão", estejam igualmente presentes em países mais ricos, como é o caso do Japão, Reino Unido ou Estados Unidos da América, por exemplo. Embora quase 70\% das escolas possuíssem em 1997 pelo menos um computador ligado à Internet e cerca de 15\% das salas de aulas pudessem dispor desse recurso, verificava-se, também, sem surpresa, que em geral o seu uso não se distribuía de forma uniforme. Antes se encontrava fortemente correlacionado com algumas variáveis demográficas, tais como o nível socioeconômico e nível de formação conforme afirmam Coley, Cradler, Engel, (1997), citados por Hoffman; e Novak (1998), ou em casos pontuais de escolas excepcionalmente bem equipadas que todos nós conhecemos e em que se continua a ensinar como se ensinava e a aprender como se aprendia. Não será, portanto, apenas uma questão de recursos financeiros, muito embora não se possam ignorar as desigualdades estruturais e funcionais que daí obviamente decorrem.

\section{Razões derivadas das próprias tecnologias e do elevado ritmo de desenvolvimento tecnológico}

Para além do que se disse a propósito dos argumentos centrados no custo das tecnologias, a democratização do uso é para outros uma questão de caráter essencialmente tecnológico, associada, em larga medida, ao estado de desenvolvimento atingido num determinado momento. De fato, para além de uma evidente dependência do grau de desenvolvimento tecnológico verificado a cada momento, é conhecida a inexorável rapidez com que os equipamentos informáticos ficam obsoletos, com as conseqüências nefastas para uma Escola que em regra não está bem equipada e dificilmente pôde dispor do tempo de experimentação e maturação de cada nova tecnologia disponível. Assim, talvez mais do que possuir o "último grito" tecnológico, a questão principal seja saber como tirar partido e rentabilizar qualquer tecnologia, mesmo que "ultrapassada", pelo menos segundo os critérios e padrões das empre- 
sas que, numa lógica comercial, criam necessidades, muitas vezes inexistentes, de aquisição de novos equipamentos.

De sinal contrário ao que se pode inferir do ponto anterior sobre um deficiente e inadequado, mas também muitas vezes anacrônico uso das tecnologias, referem-se os mais diversos exemplos bem-sucedidos de uso de tecnologias menos atualizadas e até ultrapassadas. Exemplos de sucesso e de "boaspráticas" continuam a acontecer nas nossas escolas e talvez aí resida uma das "pistas", se não diretamente para a resolução do problema, pelo menos para o estudo e desenvolvimento de investigação nesta área.

Como aconteceu com outras tecnologias no passado, o cenário mais comum é o de se verificar um momento inicial de grande adesão e excitação sobre o potencial de cada nova tecnologia, para depois se ver que o entusiasmo vai definhando até que, por vezes, desaparece, não resultando daí conclusão efetiva sobre se há de fato ganhos em termos de resultados de aprendizagem e, muito menos, em termos de uma utilização que se diferencie na forma e nos objetivos do que já se fazia com os meios tradicionalmente utilizados.

Para além das questões referentes ao cuidado com que se procede à avaliação de muitas experiências pedagógicas que, como é sabido, nem sempre existe ou não é feita com o rigor exigido, parece haver, nesta perspectiva, sobretudo um enfoque nas capacidades técnicas inerentes à nova tecnologia, nos seus atributos e no que ela consegue fazer, e não nas suas potencialidades pedagógicas e didáticas, ou seja, o que com ela alunos e professores podem realizar, o que com ela se pode aprender e como.

A questão essencial não residirá, pois, nos atributos que fazem de uma determinada tecnologia uma nova tecnologia, mas a de nos interrogarmos sobre quais as mais-valias que ela traz para o processo de aprendizagem. Dito de outra forma, como poderão os professores ensinar melhor e os alunos aprender de modo mais eficiente.

\section{Razões de natureza política e de política educativa}

Para outros ainda, a democratização das tecnologias é essencialmente uma questão política uma vez que, mesmo que seja determinante a vontade dos decisórios e seja a esse nível normalmente reconhecida a importância das TIC na Sociedade e na Escola dos nossos dias, nem sempre o discurso oficial se faz corresponder às medidas que, em termos práticos, tornariam possível a sua apropriação e rentabilização pelas escolas.

A análise das discrepâncias entre os enunciados políticos e os recursos efetivamente disponibilizados numa determinada situação concreta poderão ser, também neste domínio, uma fonte de informação interessante e que 
importa considerar na reflexão sobre a problemática da democratização do acesso as TIC. Sendo visível em programas de governo e noutros textos políticos de diferentes países, a preocupação com a integração das TIC em contexto escolar resume-se, essa questão, no entanto, em grande parte das vezes, há medidas relacionadas apenas com o equipamento e apetrechamento das escolas. Na senda do que outros países desenvolvidos têm feito e numa competição algo desenfreada para ver quem chega primeiro (creio que não se sabe muito bem onde) o Canadá anunciou, por exemplo, que pretende tornar-se o país com maior percentagem de escolas ligadas à Internet do mundo inteiro, tendo atingido em 1999 um total de 16,5 mil escolas. Nos Estados Unidos da América, por seu turno, tinha sido estabelecido dar prioridade à ligação de todas as salas de aula e bibliotecas à Internet até ao final do mandato do Presidente Clinton.

Uma observação mais atenta revela que o discurso oficial, geralmente com preocupações de natureza macro, apóia-se em argumentos relacionados com a modernização e com o aumento da produtividade, funcionando as TIC como indutoras de coesão social, ou seja, de igualdade de condições e de qualidade de vida para os cidadãos. O mesmo parece não acontecer, no entanto, no que se refere à Escola, não só em termos de eficácia e êxito na criação de novas dinâmicas de funcionamento e de mudança, como, em última instância, em termos de igualdade de oportunidades. A comparação entre modelos de implantação e disseminação das tecnologias de tipo "top-down" e "bottom-up" poderá ser, aliás, bastante esclarecedora sobre o real impacto de cada uma das abordagens (pontos fortes e fracos, implicações, etc.). A título de exemplo, um recente estudo sobre o grau de desenvolvimento dos diferentes países da União Européia faz depender exatamente desse fator à diferença de nível de desenvolvimento existente entre os chamados países do Norte (Suécia, Dinamarca, Finlândia, Reino Unido) e os países do Sul (Portugal, Espanha, Grécia), com vantagem óbvia para os primeiros, cujas políticas de disseminação das tecnologias seguem o modelo "bottom-up" (Relatório MESO, 1998, p. XI - realizado para a DG XXII da Comissão Européia, e que tem como principal finalidade observar o desenvolvimento do software multimídia educativo no mercado europeu).

\section{Razões com base cultural e de natureza psicológica}

Razões de natureza cultural e psicológica são também muitas vezes utilizadas como argumento para justificar o atraso que se verifica na Escola, em termos de utilização efetiva das TIC. Para além de fatores de matriz eminentemente cultural, como a resistência à mudança e a inércia própria da 
instituição escolar, aliás, abundantemente estudados e normalmente referidos como justificação para "atrasos" de outra índole, este tipo de justificações desloca para os diferentes agentes educativos em particular a responsabilidade do atual estado de coisas nomeadamente em termos da sua incapacidade de inovação e mudança.

Enquanto os três primeiros grupos de razões apresentados se situam, sobretudo fora da Escola, os defensores desta perspectiva parecem encontrar no interior da própria instituição escolar os motivos para as discrepâncias relativamente à Sociedade. Discrepâncias que em vez de diminuírem, vão se avolumando e parecem perpetuar-se!

As atitudes dos professores, nomeadamente de indiferença, resistência ou até rejeição a estes novos meios e ferramentas de trabalho, são um exemplo dos argumentos que costumam ser avançados externamente para justificar o fracasso e que a própria investigação, aliás, ainda que de forma pouco expressiva ou pelo menos inconseqüente, tem se encarregado de vir realçando. O receio dos professores de poderem vir a ser integralmente substituídos pela máquina era o exemplo clássico das razões apontadas, pelo menos durante os primeiros anos de expansão do computador em território tradicionalmente dominado pelo professor. Embora não se saiba ao certo até que ponto esse receio terá desaparecido, ante a evidência de que o computador por si só não garante qualquer tipo de aprendizagem, o que segundo diferentes estudos parece ser incontestável é a reduzidíssima porcentagem de professores que dele fazem uso, não apenas como ferramenta de trabalho pessoal, mas, sobretudo, como meio ou ferramenta de aprendizagem dos seus alunos.

A esse receio é freqüente juntar também um outro receio do professor relativamente à utilização das tecnologias - o de ser ultrapassado pelos próprios alunos. Seria essa a razão principal para não utilizar ferramentas que não conhece bem ou que, mesmo conhecendo, o colocariam em risco, pois rapidamente poderia ser ultrapassado pelos alunos, quer em termos de competências de utilização, quer mesmo em termos das aprendizagens propriamente ditas com essas novas ferramentas. É, aliás, uma situação que se verifica em muitos casos que conhecemos, de que ouvimos falar ou de que a própria investigação dá conta.

A estes receios e inseguranças poder-se-á acrescentar uma fonte de preocupação mais recente, essa sim bastante real e de que alguns professores têm vindo a tomar consciência. A preocupação de virem a ser substituídos efetivamente, não por máquinas como no primeiro caso, mas por outros professores, mais bem preparados, sem complexos sobre a utilização destas novas ferramentas e com competências específicas para delas tirar partido, colocando-as, sobretudo, a serviço do que é fundamental, a aprendizagem.

Embora seja extremamente importante levar em conta a questão das 
atitudes dos professores e de outros agentes educativos, facilmente aceitaremos que é um aspecto que também não esgota as respostas ao problema e que outros fatores terão de ser encontrados para compreender o atraso da Escola e a desigualdade de oportunidades que tais situações potencialmente acarretam.

\section{Uma abordagem multifacetada e globalizante}

Embora sucinta, a reflexão acabada de fazer leva-nos a concluir que a análise da problemática do acesso às tecnologias nos remete para outro lugar na procura das respostas às interrogações que acabam por não ser respondidas de forma satisfatória apenas com as perspectivas enunciadas. Alguns exemplos conhecidos de todos nós mostram que nem sempre políticas educativas favoráveis, escolas bem equipadas e professores motivados são ingredientes suficientes para se alcançarem os objetivos de utilização das novas tecnologias enquanto ferramentas de aprendizagem. A resposta terá de ser encontrada no seio da própria Escola e envolver todos quantos, de uma maneira ou de outra, nela intervêm. Como contributo para esta reflexão, poderá ter interesse analisar alguns aspectos que muitas vezes parecem ser ignorados ou deficientemente considerados, quer em termos de diagnóstico, quer em termos de planejamento e intervenção e que poderão contribuir para uma abordagem multifacetada e globalizante do fenômeno em apreço.

\section{Educação formal, novas tecnologias e o poder dos alunos}

Sendo evidente o crescente desfazimento da Escola relativamente às mudanças tecnológicas que ocorrem no mundo em que vivemos, não apenas em termos de uso das tecnologias e das suas potencialidades de comunicação, por exemplo, mas também ao nível dos próprios conteúdos tratados e das formas de acesso à informação e ao conhecimento, pode afirmar-se que a cultura transmitida pela instituição escolar tem cada vez menos a ver com a cultura que os alunos vivem e adquirem fora das aulas.

No caso concreto das novas tecnologias de informação e comunicação são curiosamente os próprios alunos quem mais partido tiram, em muitos casos de forma independente, dos recursos tecnológicos que as escolas já possuem. Quando diretamente inquiridos sobre o assunto, os alunos são, aliás, particularmente críticos sobre o papel da escola e dos professores pelo menos em termos de facilitação do trabalho com o computador. Foi por exemplo uma das conclusões de um estudo efetuado em Portugal por Cardoso, 
Peralta e Costa (2001) com o objetivo de caracterização do tipo de utilização que os alunos fazem do computador e da sua percepção sobre a qualidade dos produtos. Este estudo, desenvolvido no âmbito do Projeto PEDACTICE durante o ano de 1999, incidiu numa amostra de 77 alunos dos diferentes níveis de ensino de escolas da região de Lisboa e arredores (COSTA, 1999; COSTA, et al., 1999; COSTA, 2001).

São normalmente as crianças e os jovens que mais fácil e rapidamente aderem às enormes potencialidades dos computadores, fato que para alguns constitui uma das razões para a sua grande aceitação também na Educação, proposta por Jonassen (1999), Papert (1996) e Laurillard (1993). Papert chega mesmo a falar do "poder das crianças" como um dos fatores decisivos de mudança da Escola. Segundo eles, todas as crianças que têm um computador em casa exercem uma forte pressão e são agentes de mudança na própria Escola.

Ultrapassadas algumas barreiras e resistências iniciais, os problemas são agora de outra natureza, acentuando-se cada vez mais a necessidade de todos os intervenientes no processo educativo terem uma idéia clara não apenas das potencialidades das "novas ferramentas", mas principalmente das formas como estas podem ou devem ser integradas no quotidiano das escolas.

Muito embora o cenário otimista de que é uma questão que não constitui problema dado a facilidade com que os alunos aprendem e manipulam estas novas ferramentas (é uma questão de gerações - dizem alguns), resta-nos a preocupação de saber até que ponto a Escola está disposta a lidar também com estas aprendizagens e até que ponto está disposto - e será capaz! - de as assumir, de as promover e de liderar o próprio processo de mudança. Dependendo do êxito pessoal, social e profissional dos jovens das competências tecnológicas que a escola for capaz de lhes proporcionar, e sendo a "info-exclusão" uma das maiores ameaças da chamada Sociedade da Informação em que vivemos, espera-se no mínimo que a Escola não seja ela própria geradora de novas exclusões sociais, antes seja capaz de utilizar as tecnologias e as suas potencialidades de acesso à informação e ao conhecimento, de forma a anular ou reduzir as existentes. O que pode ou deve ser feito para atingir esse objetivo é uma questão que por agora se deixa em aberto e que noutro contexto tentaremos abordar.

\section{As mudanças na educação e o papel das tecnologias na aprendizagem}

Mesmo aceitando que o computador pode desempenhar um papel benéfico no processo de aprendizagem e embora isso possa ser conseguido de formas muito diferenciadas, dependendo das perspectivas e fundamentos 
com que cada uma das abordagens concebe a aprendizagem, a evidência é que a utilização que se faz hoje do computador nem sempre tira partido das suas reais potencialidades em termos de alteração na forma como as pessoas aprendem (PAPERT, 1996).

Como Papert sublinha a esse propósito, é no mínimo estranho que com novos recursos tão poderosos, como é o caso do computador, que em si mesmo poderiam constituir um fator de mudança substancial na forma de aprender, se continue na escola a fazer o mesmo tipo de trabalho que se fazia antes desses recursos existirem, visando ao mesmo tipo de objetivos e sem que ocorra qualquer tipo de evolução (1996). Tal como tradicionalmente acontecia, o papel da tecnologia reduz-se ainda na maior parte dos casos a fornecer a informação previamente selecionada e organizada, como se de um professor se tratasse, e em que o papel do aluno se limita também a receber e a assimilar essa mesma informação (JONASSEN; PECK; WILSON, 1999).

Para Papert (1996), mais do que uma utilização do computador como forma de auxiliar as estratégias de ensino até então utilizadas, a mudança teria de ser no sentido de equacionar o uso desses poderosos recursos como suporte ao pensamento e desenvolvimento intelectual e social dos indivíduos e, sobretudo, como fator indutor de uma "nova cultura de aprendizagem", não apenas e globalmente em maior sintonia com um mundo em transformação constante, mas também mais próxima e decorrente dos recentes desenvolvimentos na forma de pensar e equacionar o ensino e a aprendizagem e que, muito sinteticamente, poderíamos caracterizar: de um ensino centrado no professor a uma aprendizagem construída pelo próprio aluno; de uma estrutura fechada a uma estrutura aberta e dinâmica do currículo; do aluno enquanto elemento do grupo (turma) ao aluno enquanto individualidade; da utilização de materiais dirigidos ao grupo à utilização de produtos e materiais adequados a uma aprendizagem individualizada.

Embora no passado se tenha assumido que um bom ensino é a chave para uma boa aprendizagem, é hoje mais claramente aceite que a aprendizagem é o grande objetivo de qualquer intervenção pedagógica e que deve ser uma atividade a realizar fundamentalmente pelo aluno. O papel do professor deve ser o de estruturar e proporcionar situações e experiências em que essa aprendizagem possa ser feita de forma ativa, significativa e construída pelo próprio aluno.

Em termos de estratégias de trabalho, será necessário proporcionar alternativas fechadas para os métodos característicos do ensino tradicional, em que os alunos sejam envolvidos e possam ter uma crescente participação na tomada de decisão, não apenas sobre os conteúdos que querem estudar, mas também sobre as formas de o fazer e em que os professores sejam, sobretudo, capazes de os ajudar a pensar criticamente, a aprender como identificar 
e resolver problemas, a estabelecer objetivos e regular a aprendizagem (aprender a aprender), a avaliar os resultados do seu trabalho. Com a melhor compreensão sobre o que é aprender, a atenção deveria centrar-se fundamentalmente na pessoa do aluno, naquilo que o aluno faz e não no que é feito para o aluno. Enquanto que tradicionalmente a maior parte das experiências de aprendizagem é baseada e dirigida ao grupo (turma), sob o controle direto e responsabilidade única do professor, o aluno terá de ser visto como sendo capaz de tomar iniciativa e de se envolver ativamente na aprendizagem, de selecionar os métodos de estudo mais adequados, de realizar as tarefas e fazer uso dos recursos apropriados, de avaliar o trabalho desenvolvido e os seus resultados.

O consenso sobre a necessidade de individualização da aprendizagem conduziria, por seu lado, à necessidade de utilização de uma grande variedade de materiais e recursos. Em primeiro lugar, porque havendo diferentes modos de aprender, também certos tipos de materiais parecem ser mais eficazes para uns alunos do que para outros; em segundo lugar, porque certos tipos de materiais e recursos podem eles próprios ser mais adequados do que outros para o estudo de uma determinada matéria. Não seria, em suma, apenas uma questão de diferenciar e diversificar os materiais que são utilizados para apoiar a aprendizagem, mas de adequar esses materiais a diferentes estilos de aprendizagem e a uma aprendizagem que é realizada, com autonomia, pelos próprios alunos. No caso concreto dos materiais e produtos associados aos computadores, quer do ponto de vista off-line, quer do ponto de vista online, a questão essencial reside em saber até que ponto esses materiais foram efetivamente desenhados e/ou são utilizados para apoiar uma "aprendizagem profunda”. Segundo Duarte (1999), define-se por uma elevada motivação intrínseca para a tarefa e por um processamento cognitivo de nível superior (i.e. assente na compreensão), estando associada a um produto de aprendizagem de qualidade elevada (i. e. melhor retenção da informação e maior facilidade na sua aplicação) ou, se pelo contrário, desencadeiam uma "aprendizagem superficial" por Laurillard (1993) como parece ser o caso de muitos materiais multimedial hoje disponíveis.

Uma das propostas que mais se enquadra nesta perspectiva é a de que alguns autores apelidam de "ferramentas cognitivas" ("Mindtools") e que, numa perspectiva construtivista da aprendizagem, Jonassen designa por "aprender com tecnologias" (JONASSEN, 1996). Segundo este autor, as ferramentas cognitivas podem ser todas as tecnologias que facilitam o pensamento crítico, que permitem uma aprendizagem significativa e que envolvem ativamente os alunos na construção do conhecimento e não na reprodução; na conversação e não na recepção; na articulação e não na repetição; na colaboração e não competição; na reflexão e não na prescrição. 
Poderá ser, aliás, um bom contributo retomar a classificação proposta por este autor, pois possui a vantagem, pelo menos relativamente a outras tipologias mais clássicas, de nos ajudar a compreender não só os diferentes tipos de utilização possíveis em função da forma de encarar a aprendizagem, mas também o tipo de trabalho que com elas pode efetivamente ser realizado e as formas adequadas de preparar os professores, ou aprender a partir da tecnologia (learning from), em que a tecnologia apresenta o conhecimento sendo o papel do aluno receber esse conhecimento como se ele fosse apresentado pelo próprio professor (ensino assistido por computador (EAC), mas também filmes educativos, tutoriais, aplicações drill-and-practice, ensino programado, entre outros); aprender acerca da tecnologia (learning about), em que a própria tecnologia constitui ela própria objeto de aprendizagem (Computer Literacy; conhecimentos e competências necessários para professores e alunos poderem utilizar uma determinada tecnologia); aprender pela tecnologia (learning by), em que o aluno aprende ensinando o computador (programando o computador por meio de linguagens como BASIC ou o LOGO); aprender com a tecnologia (learning with), em que o aluno aprende usando as tecnologias como ferramentas que o apóiam no processo de reflexão e de construção do conhecimento (ferramentas cognitivas). Neste caso, a questão determinante não é a tecnologia em si mesmo, mas a forma de encarar essa mesma tecnologia, usando-a, sobretudo, como estratégia cognitiva de aprendizagem.

\section{Em jeito de síntese}

Partindo da reflexão em torno de algumas interrogações, defendeuse aqui a idéia de que o efetivo acesso às tecnologias é essencialmente uma questão de natureza pedagógica que passa, sobretudo, por uma preparação adequada dos professores e pelas condições das escolas para os alunos poderem tirar partido dos computadores enquanto ferramentas de aprendizagem. Utilizou-se como base da reflexão o contexto mais amplo da utilização pedagógica das TIC não só para evitar cair no mesmo tipo de erros do passado, em que só parecia interessar aquela que era, em cada momento, a última "novidade tecnológica", mas também porque me parece que a questão de fundo não reside nas potencialidades técnicas de cada nova tecnologia, antes na forma como ela é equacionada pela própria Escola e como esta é capaz de a integrar no seu seio.

Mais do que certezas ou caminhos únicos e exclusivos, essa integração está cheia de dúvidas e incertezas que decorrem de uma sociedade ela própria enfrentando desafios nunca antes vividos, não parecendo que seja 
possível encontrar uma forma única de o fazer, nem de isso depender apenas de um clima político e social favorável ou mesmo da generalização dos computadores pelas salas de aula com acesso a todos os alunos.

Apesar de se reconhecer que a existência de pelo menos um computador por sala de aula poderia vir a constituir um contributo decisivo para facilitar a mudança, sossegando assim grande parte de decisores e analistas, estou em crer que se agravariam muitos dos problemas já hoje identificados e novos e mais sérios problemas surgiriam, correndo-se o risco de potenciar a incapacidade já demonstrada e as insuficiências já identificadas.

Sem prejuízo dos necessários investimentos estruturais e materiais, a mudança depende, pois, fundamentalmente, do investimento que se fizer ao nível dos agentes educativos, de forma a que essa mesma mudança seja interiorizada e assumida por todos quantos intervêm no sistema e, ao seu nível, possam contribuir para alterar o atual estado de coisas.

\section{Referências}

CARDOSO, A.; PERALTA, H.; COSTA, F. O ponto de vista dos alunos sobre o uso de materiais multimédia na escola. In: ESTRELA, A.; FERREIRA, J. Tecnologias em educação. Lisboa: Secção Portuguesa da AFIRSE, 2001. p. 741-762.

COLEY, R.; CRADLER, J.; ENGEL, P.. Computers and classrooms: the status of technology in US schools. Princeton, NJ: ETS Policy Information Report. ETS Information Center, 1997.

COSTA, F.; NUNES, M.; MAIA, M.; DOMINGUES, M. Avaliação de Software: multimédia educativo como estratégia de formação de professores. In: In: ESTRELA, A.; FERREIRA, J. Tecnologias em educação. Lisboa: Secção Portuguesa da AFIRSE, 2001. p. 601-619.

COSTA, F. Educational multimedia in compulsory school: from pedagogical assessment to product assessment. Projecto PEDACTICE. In: SIMPÓSIO IBÉRICO DE INFORMÁTICA EDUCATIVA, 1 . Anais... Aveiro, Set. 1999. (Actas).

COSTA, F.; PERALTA, H.; CARDOSO, H.; DUARTE, A.; VISEU, S.; PEREIRA, V.; RODRIGUES, E.; VALÉRIO, O. Educational multimedia: contributions for the pedagogical efficiency and the quality assessment. Lisbon: Pedactice. In: PEDACTICE CONFERENCE. Proceedings ... Edinburgh: Scotland, Oct 1999, Deliverable 5.1, 4th.

DRUIN, A.; SOLOMON, C. Designing multimedia environments for children. New York: John Wiley; Sons, 1996. 
DUARTE, A.. Meta-aprendizagem assistida por computador: a informática ao serviço do aprender a aprender. In: In: SIMPÓSIO IBÉRICO DE INFORMÁTICA EDUCATIVA, 1 . Anais... Aveiro, Set. 1999. (Actas).

EUROPEAN COMISSION. Teaching and learning: towards the learning society: white paper on education. Bruxelas: Gabinete das Publicações Oficiais da Comunidade, 1995.

HARMON, A. Net day volunteers back to wire schools for Internet. New York Times, n: 25, Oct. 1997.

HOFFMAN, D.; NOVAK, T. Bridging the digital divide: the impact of race on computer access and Internet use. Science, n: 17, Apr. 1998.

JONASSEN, D. Computers in the classroom: mindtools for critical thinking. Columbus, OH: Merrill: Prentice Hall, 1996.

; PECK, K.; WILSON, B. Learning with technology: a constructivist perspective. Columbus, OH: Merrill: Prentice Hall, 1999.

LAURILLARD, D. How can learning technologies improvelearning? paper presented at the Higher education transformed by learning technology Swedishbritish workshop. Sweden: University of Lund, 1993.

PAPERT, S. A Família em rede. Lisboa: Relógio de Água, 1997.

PERALTA, H.; DUARTE, A.; COSTA, F. Educational multimedia: contributions for the definition of pedagogical efficiency. In: PEDACTICE CONFERENCE, 2 nd., Proceedings... Lisbon: Landau, Germany, Apr .1999). (Internal paper). 